\title{
Current Levels and Composition Profiles of Emerging Halogenated Flame Retardants and Dehalogenated Products in Sewage Sludge from Municipal Wastewater Treatment Plants in China
}

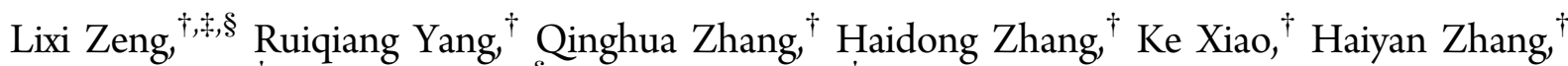 \\ Yawei Wang, ${ }^{* \dagger}$ Paul K.S. Lam, ${ }^{\S}$ and Guibin Jiang ${ }^{\dagger}$
}

${ }^{\dagger}$ State Key Laboratory of Environmental Chemistry and Ecotoxicology, Research Center for Eco-Environmental Sciences, Chinese Academy of Sciences, Beijing 100085, China

${ }^{\ddagger}$ School of Chemistry and Chemical Engineering, University of Chinese Academy of Sciences, Beijing 100049, China

${ }^{\S}$ State Key Laboratory in Marine Pollution, City University of Hong Kong, Kowloon, Hong Kong Special Administrative Region, China

Supporting Information

\begin{abstract}
Occurrence of new toxic chemicals in sludge from wastewater treatment plants (WWTPs) is of concern for the environment and human health. Alternative halogenated flame retardants (HFRs) are a group of potentially harmful organic contaminants in the environment. In this study, a nationwide survey was carried out to identify the occurrence of HFRs and their potential dehalogenated products in sewage sludge from 62 WWTPs in China. Of all 20 target chemicals analyzed, decabromodiphenyl ethane (DBDPE), hexabromocyclododecane (HBCD) and 1, 2-bis (2,4,6-tribromophenoxy)ethane (BTBPE) were detected in all sludge samples, and the concentrations were in the range of $0.82-215,0.09-65.8$, and $0.10-2.26 \mathrm{ng} \mathrm{g}^{-1}$ d.w., respectively. Dechlorane Plus (DP) was found in 60 of 62 samples, and the concentration ranged from nd- $298 \mathrm{ng} \mathrm{g}^{-1}$ with a mean of $18.9 \mathrm{ng} \mathrm{g}^{-1}$ d.w. The anti-DP fractional abundance $f_{\text {anti }}(0.79)$ in the samples was much higher than

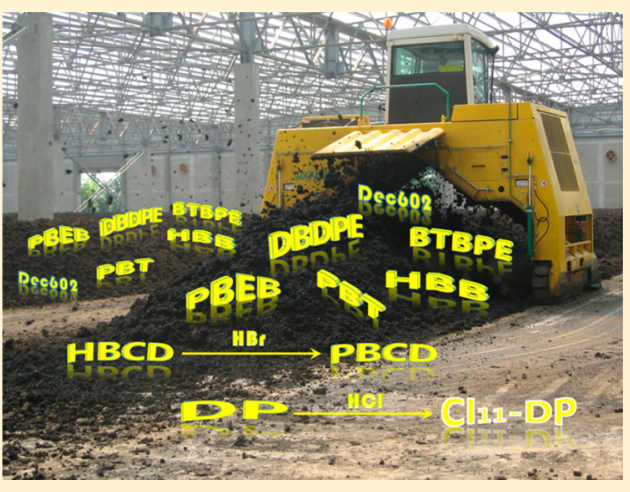
the commercial DP composition $\left(f_{\text {anti }}=0.59\right)$, indicating a stereoselective degradation. Comparison with global sludge concentrations of HFRs indicate that China is at the medium pollution level in the world. Principal components analysis revealed that strong correlations existed between ln-transformed concentrations (natural logarithm) of the dominant BFRs and total organic carbon (TOC) as well as industrial wastewater proportion, influent volume and serving population. Significant linear relationships $(R=0.360-0.893, p<0.01)$ were found among emerging brominated flame retardants (BFRs), suggesting their common commercial applications and release sources to the environment. Two kinds of dehalogenated products, pentabromocyclododecane $(\mathrm{PBCD})$ and undecachloropentacyclooctadecadiene $\left(\mathrm{Cl}_{11}-\mathrm{DP}\right)$, derived from $\mathrm{HBCD}$ and $\mathrm{DP}$, were also identified in sewage sludge for the first time.
\end{abstract}

\section{INTRODUCTION}

Halogenated flame retardants (HFRs) mainly include two classes of commercial organobromine and organochlorine compounds for fire-retardant application in common household objects such as furniture, mattresses, textiles, plastics, resins, baby products, and electronic equipment. ${ }^{1}$ Many HFRs have been synthesized and used extensively in high volumes for a decade or more and therefore prevalent in the environment. ${ }^{2,3}$ Of the commercialized HFRs, brominated flame retardants (BFRs) such as polybrominated diphenyl ethers (PBDEs) were most widely used. ${ }^{4}$ However, due to the environmental and public health concerns, penta-BDE and octa-BDE have been banned under the Stockholm Convention on Persistent Organic Pollutants (POPs) and Deca-BDE are also being phased out in many countries. ${ }^{2}$

Restrictions of PBDEs have led to the increasing production and use of other alternative HFRs. ${ }^{5}$ As a result, a number of emerging HFRs have been widely identified in diverse environmental matrices worldwide and pose a potential risk to the environment and human health. ${ }^{6}$ Representative emerging HFRs include 1,2-bis(2,4,6-tribromophenoxy)-ethane (BTBPE), pentabromoethylbenzene (PBEB), decabromodiphenyl ethane (DBDPE), tetrabromo-o-chlorotoluene (TBOCT), hexabromocyclododecane (HBCD), 1,2-dibromo4-(1,2-dibromoethyl) cyclohexane (TBECH), polybrominated biphenyls (BB153 and BB209), hexabromobenzene (HBB), pentabromotoluene (PBT), hexachlorocyclopentadienyl dibromocyclooctane (HCDBCO), tetrabromo- $p$-xylene ( $\mathrm{pTBX}$ ), tribromobenzene (TBB) and Dechlorane Plus (DP)., ${ }^{2,7,8}$

Received: July 19, 2014

Revised: October 5, 2014

Accepted: October 6, 2014

Published: October 6, 2014 
Among these emerging HFRs, DBDPE, BTBPE, HBCD, and $\mathrm{DP}$ were the most frequently detected contaminants in the Chinese environment. $^{9-12}$

DBDPE is structurally similar to BDE209 and has been introduced into the market as a principal alternative for DecaBDE since the early 1990s. ${ }^{7}$ Both DBDPE and BDE209 are mainly used in textile and plastic applications. Recently, DBDPE have been frequently detected in diverse environmental matrices. ${ }^{11,12} \mathrm{Zhu}$ et al. reported an increasing trend substitution of deca-BDE for DBDPE in China. ${ }^{13}$ HBCD is widely used as an additive BFR in the polystyrene foams, thermal insulation, and electrical products, which have been identified to be ubiquitous contaminants and now considered as POPs candidates. ${ }^{1,9,14}$ Polybromobenzenes including HBB, PBT, PBEB were manufactured from 1980s and have been used in polyester, latex, textiles, electronics, and plastic goods. ${ }^{15}$ Some polybromobenzene pollutants have been demonstrated to be bioaccumulative and toxic. ${ }^{16,17} \mathrm{DP}$ is a highly chlorinated flame retardant with a similar structure to the pesticide mirex and consists of two isomers (syn- and anti-DP). It was suggested as a substitute to Deca-BDE in polymeric applications since the 1960 s. $^{18}$ DP analogues including Dechloranes 602 (Dec602), 603 (Dec603), and 604 (Dec604) were commercialized as fire retardants in the 1970s. DP is now categorized by the U.S. EPA as a high production volume chemical with the annual U.S. production up to 450 tons. $^{3}$ Dec602, 603, and 604 are on the Canada's Nondomestic Substances List. Since the first reports on environmental occurrence of DP in $2006^{19}$ and other Dechloranes in 2009, ${ }^{20}$ subsequent studies have indicated that DP and some analogues are potentially worldwide contaminants. $^{3,21}$

Wastewater treatment plants (WWTPs) are commonly considered as a major sink for many organic contaminants through receiving domestic and/or industrial sewage. ${ }^{22,23}$ Due to high octanol-water partition coefficient $\left(K_{\mathrm{OW}}\right)$ and organic carbon-water partition coefficient $\left(K_{\mathrm{OC}}\right)$, HFRs are preferentially disposed into sludge partition during wastewater treatment. $^{24,25}$ Therefore, sewage sludge can be an excellent medium for determining the environmental occurrence and discharge of emerging HFRs, which could also re-enter the ambient environment via biosolids application. ${ }^{25,26}$ Detailed investigations on several emerging HFRs in sludge have been carried out in Spain, ${ }^{25,27}$ Korea, ${ }^{22,28}$ and the U.S., ${ }^{29}$ whereas only limited number of samples or types of HFRs have been analyzed in other countries. ${ }^{30-34}$ However, very few studies have been reported on alternative HFRs and their potential degradation products in sewage sludge from China. ${ }^{11}$

China is now one of the world's major flame retardants manufacturers with an total annual production up to 200000 tons. ${ }^{35,36}$ Among them, the annual production volumes for Deca-BDE, DBDPE, HBCD and DP have been reached 20000 , 12000,7500 , and $300-1000$ tons in recent years, respectively. ${ }^{11,14,37}$ BTBPE, HBB, and PBT are also produced and used in China, but their production volumes are not available. ${ }^{10}$ No manufacturing information is available in China for other HFRs to date. China is also one of the world's largest consumers of flame retardants with an annual growth rate at $7 \%$ in consumption demand. ${ }^{38,39}$ With the increasing production and usage for HFRs in China, discharges from industrial process and emission from household products could result in elevated levels of emerging HFRs in the Chinese environment. ${ }^{9,11,40,41}$ Since WWTP usually receives input from large communities or commercial zones, the resulting sewage sludge can be used as an indicator for investigating the integrated emission of organic pollutants at a population based level. In this work, we carried out the first nationwide survey to determine emerging HFRs and several degradation products in sludge from WWTPs in China. The objectives of this study are to reveal current pollution levels of emerging HFRs, identify the occurrence of potential dehalogenated products in sewage sludge, examine potential factors affecting the accumulated concentrations, and evaluate environmental emission of HFRs via land-application sludge in China.

\section{MATERIALS AND METHODS}

Sample Collection. A total of 62 sewage sludge samples from municipal WWTPs representing various regions in China were collected during August 2010 to August 2013, covering 36 cities in 21 provinces and municipalities across China. The sampling map is shown in Supporting Information (SI) Figure S1. About $0.5-1.0 \mathrm{~kg}$ wet weight of the freshly digested sludge as grab samples was obtained from WWTP dehydration process, packed in aluminum foil, sealed in Ziplock bags and then immediately transported to the laboratory. All samples were freeze-dried, homogenized, and stored in a freezer at -20 ${ }^{\circ} \mathrm{C}$ until extraction. Basic characteristics of the selected WWTPs are provided in the SI Table S1, including wastewater treatment capacity, daily processing volume, serving population, sewage sources (domestic, industrial, or mixed) and biotreatment techniques during secondary treatment process as well as total organic carbon (TOC) for individual sludge samples.

Instrumental Analysis and Quantification. In this study, 13 current-use non-PBDE BFRs (TBECH, pTBX, TBOCT, PBT, PBEB, HBB, TBB, HCDBCO, BB153, BB209, BTBPE, HBCD, and DBDPE), four CFRs (syn- and anti- DP, Dec602, Dec603, and Dec604) and three dehalogenated products (pentabromocyclododecane, PBCD for $\mathrm{HBCD}$, anti-Cl $\mathrm{Cl}_{11} \mathrm{-DP}$, and anti-Cl $\mathrm{Cl}_{10}$-DP for $\mathrm{DP}$ ) were measured in sludge samples (full name and structure information on the compounds are shown in Table S2, SI). The procedures of sample extraction, cleanup, and instrumental analysis were based on our previously developed methods with minor modifications. ${ }^{7,42,43}$ Briefly, 0.5-1.0 g of sample were spiked and then extracted with accelerated solvent extractor (ASE). Five $g$ of acidic silica $(40 \%, \mathrm{w} / \mathrm{w})$ was added into the extract to remove most of lipids. After primary purification, a multilayer silica column was used for further cleanup with $70 \mathrm{~mL}$ of hexane/dichloromethane $(5: 1, \mathrm{v} / \mathrm{v})$. Detailed sample preparation procedure can be found in the SI.

Target chemicals were analyzed using a high-resolution gas chromatograph/low-resolution mass spectrometer (HRGC/ LRMS, SHIMADZU2010 Ultra, Japan) with electron capture negative ionization (ECNI) in selected ion monitoring (SIM) mode. The MS ion source and interface temperatures temperature were 150 and $280{ }^{\circ} \mathrm{C}$, respectively. Helium and methane were used as carrier and reagent gas, respectively. The analytes were separated on a $15 \mathrm{~m}$ DB-5MS capillary column (0.25 mm i.d. $\times 0.1 \mu \mathrm{m}$ film thickness, J\&W Scientific, U.S.) with a constant flow rate of $1 \mathrm{~mL} / \mathrm{min}$. The GC temperature program was as follows: hold at $100{ }^{\circ} \mathrm{C}$ for $4 \mathrm{~min}$; then increase to $150{ }^{\circ} \mathrm{C}$ at $8{ }^{\circ} \mathrm{C} / \mathrm{min}$ and hold for $4 \mathrm{~min}$; finally ramp to 300 ${ }^{\circ} \mathrm{C}$ at $12{ }^{\circ} \mathrm{C} / \mathrm{min}$ and hold for $13 \mathrm{~min}$. The injection was performed with $1 \mu \mathrm{L}$ in splitless mode. The following primary/ secondary ions $(\mathrm{m} / z)$ were used for quantification and confirmation: 79/81 for all non-PBDEs BFRs, 340.8/613.6 
Table 1. Descriptive Statistics of Concentrations of the Identified Halogenated Flame Retardants and Their Selected Dehalogenated Products in Sludge from WWTPs in China (ng/g d.w.)

\begin{tabular}{|c|c|c|c|c|c|c|c|}
\hline type & analyte & $\mathrm{DF}^{a}(\%)$ & mean & median & $\mathrm{P}^{\circ} 5^{b}$ & range & $\operatorname{AP}^{c}(\%)$ \\
\hline \multirow[t]{7}{*}{ BFRs } & PBT & 82.3 & 0.07 & 0.06 & 0.20 & $\mathrm{nd}^{d}-0.29$ & 0.1 \\
\hline & PBEB & 75.8 & 0.04 & 0.04 & 0.09 & $\mathrm{nd}-0.12$ & 0.1 \\
\hline & HBB & 88.7 & 0.68 & 0.55 & 1.54 & $\mathrm{nd}-3.22$ & 0.9 \\
\hline & ВТВРЕ & 100 & 0.95 & 0.86 & 2.08 & $0.10-2.26$ & 1.3 \\
\hline & DBDPE & 100 & 52.2 & 41.1 & 154 & $0.82-215$ & 73.1 \\
\hline & $\sum \mathrm{HBCD}$ & 100 & 17.3 & 16.0 & 39.3 & $0.09-65.8$ & 24.2 \\
\hline & $\sum \mathrm{PBCD}$ & 67.8 & 0.21 & 0.20 & 0.46 & nd-0.72 & 0.3 \\
\hline \multirow[t]{5}{*}{ CFRs } & Dec602 & 14.5 & 0.02 & n.d. & 0.08 & $\mathrm{nd}-0.21$ & 0.1 \\
\hline & $\mathrm{Cl}_{11}-\mathrm{DP}$ & 41.9 & 0.18 & n.d. & 0.61 & nd -4.15 & 0.9 \\
\hline & syn-DP & 74.2 & 3.77 & 1.13 & 13.9 & nd-59.6 & 20.0 \\
\hline & anti-DP & 96.8 & 15.2 & 3.28 & 74.5 & nd-238 & 79.0 \\
\hline & $\sum \mathrm{DP}$ & 96.8 & 18.9 & 4.25 & 91.1 & nd-298 & 99.0 \\
\hline
\end{tabular}

for Dec602, 635.6/637.6 for Dec603, 79/81 for Dec604, 651.8/ 653.8 for syn- and anti-DP, $617.7 / 619.7$ for $\mathrm{Cl}_{11}$-DP, 583.8/ 585.8 for $\mathrm{Cl}_{10}$-DP, 369.7/371.7 for ${ }^{13} \mathrm{C}_{12}-\mathrm{PCB} 138$, and 507.9/ 509.9 for ${ }^{13} \mathrm{C}_{12}-\mathrm{PCB} 209$. Considering possible thermal decomposition of HBCD in GC analysis, ${ }^{7,44}$ we assessed the possible factors resulting in the thermal degradation and found the injection port temperature was a critical factor when optimizing the temperature program on a $15 \mathrm{~m}$ column (SI Figure S2). The low injection port temperature was suitable for determination of HBCD but not for sensitive determination of other high molecular weight analytes. Therefore, two injections for each sample at different injection temperature were performed in $\mathrm{GC}$ analysis $\left(220{ }^{\circ} \mathrm{C}\right.$ for $\mathrm{HBCD}$ and $\mathrm{PBCD}$ and $280{ }^{\circ} \mathrm{C}$ for other targeted HFRs, SI Figure S3). The $\alpha, \beta$ and $\gamma$-HBCD isomers could not be separated by GC, so only the sum of three isomers $\left(\sum \mathrm{HBCD}\right)$ was reported. ${ }^{7}$ All the target compounds can be well resolved with different response factors (Figure S4, SI). Due to possible interference from $2,2^{\prime}, 4,4^{\prime}, 5,6^{\prime}$-hexabromodiphenyl ether (BDE154) in analysis of $\mathrm{BB} 153$ on $15 \mathrm{~m}$ column, the qualitative results were checked on DB-XLB $(30 \mathrm{~m} \times 0.25 \mathrm{~mm}$ i.d., $0.25 \mu \mathrm{m}$ film thickness $)$ column. Quantification was performed by internal standard calibration, using the primary ion of each analyte. Seven point calibration curves with concentration from 0.2 to $200 \mathrm{ng} / \mathrm{mL}$ were used for the quantification of HFRs and potential dehalogenated products with the regression coefficients of $R^{2}$ $\geq 0.99$.

Quality Assurance and Quality Control (QA/QC). Strict quality assurance and control measures were implemented to ensure accurate identification and quantification of the analytes. All glassware was soaked in a detergent and solvent rinsed, then heated at $450{ }^{\circ} \mathrm{C}$ overnight prior to use. A procedural blank was analyzed with every batch of eight samples. The concentrations of HFRs and selected dehalogenated products in procedural blanks were all below the method detection limit (MDL). All data reported herein were not blank corrected and on a dry weight basis. Estimating the recoveries in this study was similar to that described lately. ${ }^{23}$ One sample was randomly selected for matrix spike and sample duplicate analyses, with every batch of samples analyzed. HFRs and their corresponding surrogate standards were spiked at $10 \mathrm{ng}$ and passed through the entire analytical procedure. The average recoveries of target analytes and three surrogates in spiked samples were $92.6 \pm 15.2 \%$ and $88.5 \pm 16.7 \%$, respectively. The average coefficient of variation of triplicate analyses was $\leq 18 \%$. The surrogate standard recoveries in all sludge samples $(n=62)$ ranged from $80.5 \%$ to $114.8 \%$. The concentrations reported in this study were corrected based on the surrogate recoveries. The MDL was calculated based on 5 times the signal-to-noise $(s / n)$ ratio, which ranged from 0.01 (PBT) to 0.2 (DBDPE) $\mathrm{ng} \mathrm{g}^{-1}$ for non-PBDEs BFRs, and from 0.01 (Dec602) to 0.05 (DP) ng $\mathrm{g}^{-1}$ for Dechloranes.

Statistical Analysis. The concentrations below MDL were replaced by half of the MDL. Pearson's correlation analysis was conducted to investigate the correlations among the concentrations of different HFRs and their potential dehalogenated products in sewage sludge samples. Principal component analysis (PCA) was performed to examine the relationships between HFRs in the sludge and the WWTP characteristics using the varimax rotation method with Kaiser normalization. All statistical analysis were performed using IBM SPSS Statistics 20.0 (IBM Corp, 1989-2011) and statistical significance was set at $p<0.05$ unless otherwise specified.

\section{RESULTS AND DISCUSSION}

Of all target chemicals analyzed, DBDPE, BTBPE, HBCD, PBT, PBEB, HBB, DP, Dec602 and two dehalogenated products ( $\mathrm{PBCD}$ and $\mathrm{Cl}_{11}-\mathrm{DP}$ ) could be detected in sludge from Chinese WWTPs. Other non-PBDEs BFRs, Dec603, Dec604 and the dehalogenated product $\mathrm{Cl}_{10}$-DP were all under MDL in all sludge samples. Therefore, the following discussion was focused on the detectable HFRs and emerging dehalogenated products in WWTPs. All measured concentrations were presented on a dry weight (d.w.) basis. The detailed dry-weight and TOC-normalized concentrations for individual analyte in sewage sludge are shown in the SI Table S3 and S4, respectively.

Emerging Brominated Flame Retarders and Potential Dehalogenated Products in Sludge. Statistical results of concentrations for the identified HFRs and their potential dehalogenated products in sewage sludge are summarized in Table 1 and illustrated by Box-Whisker plots in the SI Figure S5. DBDPE, HBCD, and BTBPE were more frequently detected than PBT, PBEB, and HBB. Thereinto, DBDPE was the most abundant and predominant BFR, which accounted for $73.1 \%$ of total emerging BFRs, with the range of $0.82-215 \mathrm{ng}$ $\mathrm{g}^{-1}$ (mean $52.2 \mathrm{ng} \mathrm{g}^{-1}$ ), followed by HBCD and BTBPE, with the range of $0.09-65.8 \mathrm{ng} \mathrm{g}^{-1}$ (mean $17.3 \mathrm{ng} \mathrm{g}^{-1}$ ) and $0.10-$ 
Table 2. Pearson's Correlation Matrix for Concentrations of Emerging HFRs and Their Selected Dehalogenated Products in Municipal Sludge Samples ${ }^{a}$

\begin{tabular}{|c|c|c|c|c|c|c|c|c|c|}
\hline & PBT & PBEB & HBB & BTBPE & DBDPE & $\sum \mathrm{HBCD}$ & $\sum \mathrm{PBCD}$ & $\sum \mathrm{DP}$ & $\mathrm{Cl}_{11}-\mathrm{DP}$ \\
\hline PBEB & $0.551 * *$ & & & & & & & & \\
\hline HBB & $0.552 * *$ & $0.377 * *$ & & & & & & & \\
\hline ВТВРE & $0.477 * *$ & $0.377 * *$ & $0.568 * *$ & & & & & & \\
\hline DBDPE & $0.556^{* *} *$ & $0.360 * *$ & $0.631 * *$ & $0.558 * *$ & & & & & \\
\hline$\sum \mathrm{HBCD}$ & $0.517^{* *} *$ & $0.475 * *$ & $0.612 * *$ & $0.494 * *$ & $0.893 * *$ & & & & \\
\hline$\sum \mathrm{PBCD}$ & $0.516^{* *}$ & $0.556^{* *}$ & $0.517 * *$ & $0.599 * *$ & $0.750 * *$ & $0.888^{* *}$ & & & \\
\hline$\sum \mathrm{DP}$ & 0.161 & 0.189 & 0.128 & 0.203 & 0.143 & 0.082 & -0.019 & & \\
\hline$\overline{\mathrm{Cl}}_{11}-\mathrm{DP}$ & 0.078 & 0.173 & 0.064 & $0.251^{*}$ & 0.112 & 0.053 & -0.013 & $0.921 * *$ & \\
\hline Dec602 & 0.142 & 0.216 & 0.099 & 0.148 & 0.086 & 0.047 & -0.054 & $0.982 * *$ & $0.889^{* *}$ \\
\hline
\end{tabular}

$a_{\text {The symbols }} * *$ and $*$ represent significant correlation at $p<0.01$ and $<0.05$ levels, respectively.

$2.26 \mathrm{ng} \mathrm{g}^{-1}$ (mean $0.95 \mathrm{ng} \mathrm{g}^{-1}$ ), respectively. The concentrations of DBDPE and HBCD were slightly lower than our previously reported levels of BDE-209 (not detected (nd)-1109 $\mathrm{ng} \mathrm{g}^{-1}$ with an average level of $68.5 \mathrm{ng} \mathrm{g}^{-1}$ ) in sewage sludge. ${ }^{45}$ It is noteworthy that, the nationwide average level of DBDPE in sewage sludge were far less than those (266-1995 $\mathrm{ng} \mathrm{g}^{-1}$ with average level of $\left.1183 \mathrm{ng} \mathrm{g}^{-1}\right)$ from the Pearl River Delta, which is one of the most industrialized and urbanized electronic/electrical equipment manufacturing bases in southern China. ${ }^{11}$

The emerging compounds $\mathrm{PBT}, \mathrm{HBB}$, and $\mathrm{PBEB}$ were also identified in most sludge samples but with much lower levels compared with DBDPE and HBCD. PBT and HBB were detected in 51 and 55 of the 62 samples, respectively, and their concentrations ranged between nd-0.29 and nd-3.22 $\mathrm{ng} \mathrm{g}^{-1}$, respectively. PBEB was detected in quantifiable level in 47 of the 62 samples with the range of nd-0.12 $\mathrm{ng} \mathrm{g}^{-1}$. To date, there are no comparable sludge data on the occurrence of emerging BFRs other than DBDPE and BTBPE in China. ${ }^{11}$ Considering the results in other environmental matrices, the total concentrations of PBT, HBB and PBEB in sewage sludge were comparable to those in surface sediments (nd-2.96 ng $\mathrm{g}^{-1}$ ) from Pearl River Delta. ${ }^{10}$

Significantly linear relationships $(R=0.360-0.893, p<0.01)$ were found among these emerging BFRs in sludge from these WWTPs (Table 2), suggesting their similar commercial applications and release sources in the environment. A distinguishable geographical trend of higher concentrations of emerging BFRs, especially for DBDPE and HBCD, was found in the eastern regions than the central and western regions of China (Figure 1), which was similar to the geographical distributions of OH-PBDEs and emerging quaternary ammonium compounds in sewage sludge of China in our previous works. ${ }^{46,47}$ The spatial distribution pattern might stem from high-volume usage of BFRs-containing consumer products and the corresponding industrial production and application in the eastern regions of China (Figure S6, SI). The production of DBDPE is growing rapidly in recent years as substitutes to BDE-209. ${ }^{48}$ The higher concentrations of DBDPE in sewage sludge may imply that it is likely becoming one of the major emerging BFRs in the Chinese environment. ${ }^{10}$

Identification of potential degradation and/or biotransformation products of parent compound BFRs during sewage treatment in WWTPs has raised concerns on their environmental fate and potential adverse effect to the ecosystem. In the present study, a degradation product of $\mathrm{HBCD}$, pentabromocyclododecane (PBCD) could be found in 42 of the 62 sludge samples with the concentration range of $\mathrm{nd}-0.72 \mathrm{ng} \mathrm{g}^{-1}$ and an

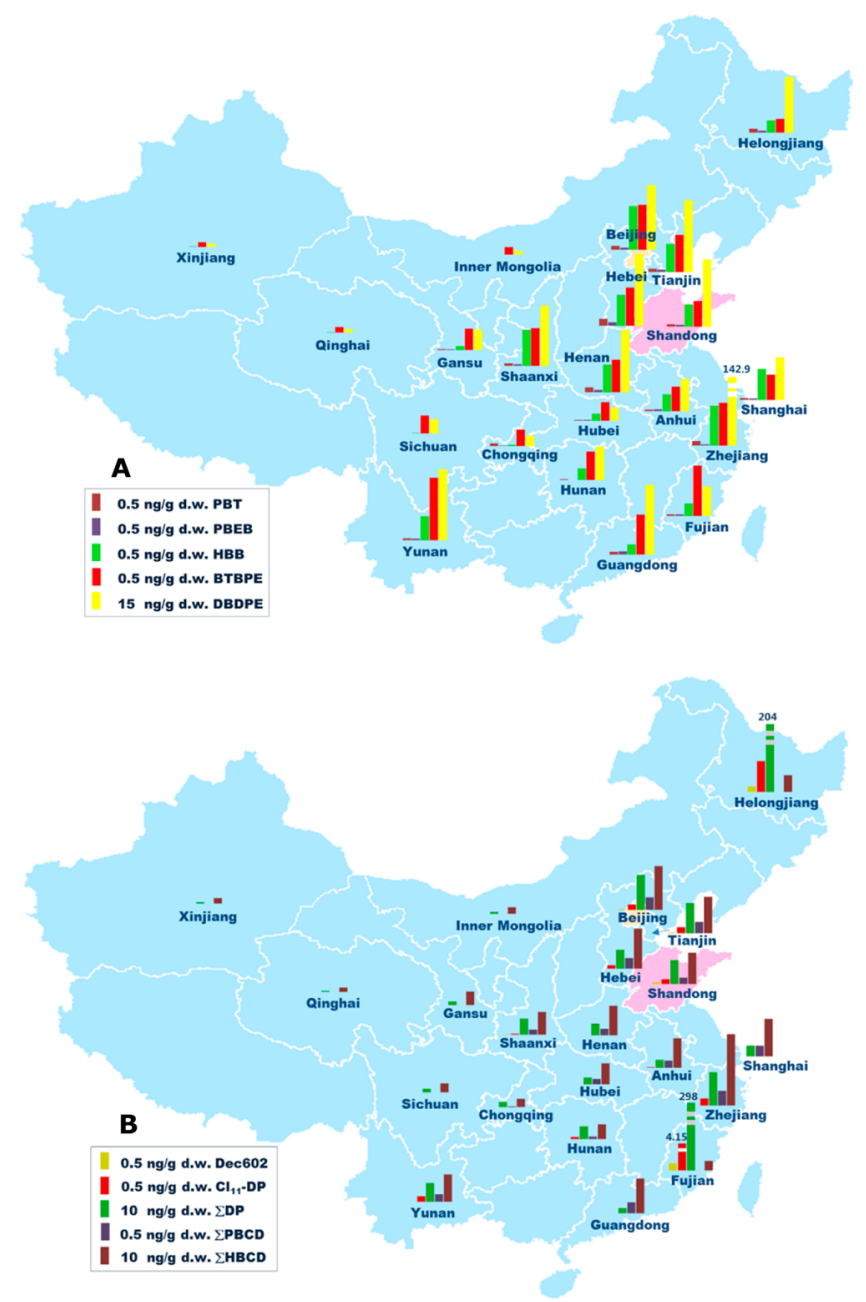

Figure 1. Spatial distributions of average levels for emerging BFRs (A), and $\sum$ HBCD, $\sum D P$ and their selected dehalogenated products $(B)$ in sewage sludge samples in different provinces/municipalities across China.

average value of $0.21 \mathrm{ng} \mathrm{g}^{-1}$. The degradation product PBCD had also been previously identified in other environmental matrices. The concentrations of $\sum \mathrm{PBCD}$ in sludge was lower than those reported in sediments (nd-20 ng g ${ }^{-1}$ ) from Japanese riverine environment ${ }^{49}$ and indoor dust (nd-6438 ng $\left.\mathrm{g}^{-1}\right)$ in $\mathrm{UK}^{50}$ Moreover, the breakable carbon-bromine bond of $\mathrm{HBCD}$ can be expected to generate significant degradation or biotransformation in biological systems. ${ }^{51}$ In the present study, a significantly high correlation between concentrations of 
$\sum \mathrm{PBCD}$ and $\sum \mathrm{HBCD}$ in the sludge samples $(R=0.888, p<$ 0.01 , Table 2) could suggest a concentration-dependent degradation of $\mathrm{HBCD}$ via reductive debromination in the sludge. Although there are a few reports on biotransformation of HBCD in biota, ${ }^{52-54}$ to our knowledge, this is the first report about the extensive occurrence of PBCD in municipal sewage sludge.

Emerging Chlorinated Flame Retarders and Dechlorinated Products in Sludge. As shown in Table 1, DP could be detected in $96.8 \%$ of the sludge samples, and the concentrations ranged from nd to $298 \mathrm{ng} \mathrm{g}^{-1}$ with a mean value of $18.9 \mathrm{ng} \mathrm{g}^{-1}$, which indicated widespread distribution of this group of compounds in the Chinese sludge. Similar to the spatial distribution of emerging BFRs (Figure 1), relatively higher concentrations of DP was found in the eastern regions, especially in coastal areas, where the higher urbanization and industrialization may contribute to the higher DP level. ${ }^{12}$ Comparing to the other targeted compounds, DP exhibited higher concentrations than $\mathrm{HBCD}$, but lower than DBDPE. Dec602 were only found in small proportions of the samples (10 WWTPs) with the maximum of $0.21 \mathrm{ng} \mathrm{g}^{-1}$ whereas Dec 603 and Dec 604 were not detected in sludge, showing less contamination by these three chemicals due to their low usage in China. No significant correlations were found between the measured concentrations of emerging BFRs and Dechloranes in sludge samples except for BTBPE versus $\mathrm{Cl}_{11}$-DP $(R=0.251, p$ $<0.05$ ) (Table 2).

For two DP isomers analyzed, the detection frequencies of anti-DP and syn-DP were $96.8 \%$ and $74.2 \%$, respectively, and anti-DP was the dominant residue observed in sludge. The antiDP fractional abundance $\left(f_{\text {anti }}\right)$ is generally used to elucidate the behavior and fate of DP in the environment, which is expressed as $f_{\text {anti }}=[$ anti-DP $] /([$ anti-DP $]+[$ syn-DP $]) .{ }^{43}$ In this study, the average $f_{\text {anti }}$ value of sewage sludge $\left(f_{\text {anti }}=0.79\right)$ was significantly higher than the commercial DP composition in the Chinese market $\left(f_{\text {anti }}=0.59\right)$, indicating a preferential depletion of syn-DP relative to anti-DP isomer during the sewage treatment processes. The high $f_{\text {anti }}$ profiles in sewage sludge were consistent with previously reported data in soil and sediment, ${ }^{14,41,55-57}$ further demonstrating that stereoselectively microbial mediated degradation of DP could lead to the relative enrichment of anti-DP in sludge, soil and sediment.

For two potential degradation products from DP analyzed, $\mathrm{Cl}_{11}$-DP [DP-1Cl] was detected in 26 of the 62 sludge samples while $\mathrm{Cl}_{10}$-DP $[\mathrm{DP}-2 \mathrm{Cl}]$ was not detected in any of the WWTPs investigated. This is consistent with the recent reports in wildlife ${ }^{58,59}$ and human beings. ${ }^{60}$ The concentrations of $\mathrm{Cl}_{11^{-}}$. DP were in the range of $\mathrm{nd}-4.15 \mathrm{ng} \mathrm{g}^{-1}$ with an average of 0.18

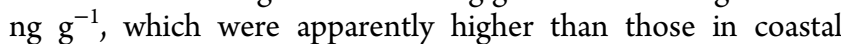
sediments (nd-0.04 $\mathrm{ng} \mathrm{g}^{-1}$ ) in north China. ${ }^{61} \mathrm{~A}$ significant correlation was also found between the concentrations of $\mathrm{Cl}_{11^{-}}$ DP and DP in sewage sludge $(R=0.921, p<0.01)$. Both high correlations between $\mathrm{Cl}_{11}$-DP vs DP and $\sum$ PBCD vs $\sum \mathrm{HBCD}$ in sewage sludge could imply that dehalogenation is a degradation pathway for HFRs during wastewater treatment.

Global Comparisons of HFR Concentrations in Sludge among Different Countries. There is still lack of environmental data about emerging HFRs, especially for BTBPE, HBB, PBEB, PBT, and their dehalogenated products, in sludge among different countries in the world. So only comparisons for the surveyed concentrations of emerging BFRs, HBCD and Dechloranes in sludge from Chinese WWTPs with those available from other countries are presented in SI Table S5-S7, respectively. As shown in SI Table S5, the mean DBDPE concentration ( $52.2 \mathrm{ng} \mathrm{g}^{-1}$ ) in sludge in China was comparable to those reported in Spain, ${ }^{25,27,31}$ Singapore, Sweden, England, Germany, the Czech Republic and South Africa, ${ }^{30}$ and comparatively higher than those in Australia, the U.S., Canada, New Zealand, ${ }^{30}$ and Norway, ${ }^{33}$ but evidently lower than the values found in Korea $\left(237 \mathrm{ng} \mathrm{g}^{-1}\right)^{22}$ and Switzerland (128 $\mathrm{ng}$ $\left.\mathrm{g}^{-1}\right){ }^{30}$ The mean sludge BTBPE concentration $\left(0.95 \mathrm{ng} \mathrm{g}^{-1}\right)$ in this study was similar to those reported for Korea (1.57 $\mathrm{ng}$ $\left.\mathrm{g}^{-1}\right)^{22}$ and Norway $\left(1.27 \mathrm{ng} \mathrm{g}^{-1}\right),{ }^{33}$ but much lower than the level found in the U.S. $\left(10.1 \mathrm{ng} \mathrm{g}^{-1}\right){ }^{29}$ The mean sludge HBB concentration $\left(0.68 \mathrm{ng} \mathrm{g}^{-1}\right)$ was equivalent to that in Spain $\left(0.44 \mathrm{ng} \mathrm{g}^{-1}\right),{ }^{25}$ but 3 orders of magnitude lower than the value in Germany (329.4 $\left.\mathrm{ng} \mathrm{g}^{-1}\right){ }^{62}$ For PBEB, a lower mean level $\left(0.04 \mathrm{ng} \mathrm{g}^{-1}\right)$ was observed in China compared to Spain $(0.25$ $\left.\mathrm{ng} \mathrm{g}^{-1}\right){ }^{25}$ No PBT concentration data in sludge are available for comparison.

As shown in SI Table S6, the mean levels of $\sum$ HBCD (17.3 $\left.\mathrm{ng} \mathrm{g}^{-1}\right)$ in this work were lower than those reported in Korea ${ }^{28}$ and European countries including Spain, ${ }^{25,63}$ Sweden, ${ }^{64}$ Switzerland, ${ }^{65}$ England, Ireland and Netherland. ${ }^{66}$ The relatively higher $\sum$ HBCD levels in European sludge might be attributed to the larger consumption in Europe in the past years. ${ }^{67}$ As shown in SI Table S7, the mean level of $\sum D P$ in sludge samples from China $\left(18.9 \mathrm{ng} \mathrm{g}^{-1}\right)$ was comparable to the concentrations reported from Spain $\left(32.5 \mathrm{ng} \mathrm{g}^{-1}\right)^{32}$ and the U.S. $\left(25 \mathrm{ng} \mathrm{g}^{-1}\right){ }^{29}$ whereas the fractional abundance $f_{\text {anti }}(0.79)$ was higher than the values in Spanish $(0.69,0.71)$ and U.S. (0.60) sewage sludge. Dec602 was sporadically detected in Chinese and Spanish sludge with similarly low concentrations, while Dec603 could be widely detected in Spain, but not found in China in the present study. ${ }^{27}$

PCA for Evaluating Potential Factors Affecting HFRs Levels in Sewage Sludge. A wide range of potential factors could influence pollutant concentrations in sludge from different WWTPs. These factors would involve treatment capacity, influent volumes, serving population, treatment techniques as well as different residential and industrial sources. $^{23,29}$ Additionally, TOC could also affect the final concentrations of pollutants in sludge. In this study, principal component analysis (PCA) was used to examine how these factors might affect the HFR concentrations in the sludge samples.

DBDPE, BTBPE, HBCD, and DP with detection frequency over 95\% were included in the analysis. PCA extracted two components with eigenvalues greater than 1 , which contributed to a total of $72.4 \%$ of the cumulative variances. Figures 2 illustrated the loading and score plots of the two principal components. In the loading plot, component 1 accounted for $59.4 \%$ of the total variance and had high correlation with DBDPE, HBCD, TOC, IWF (industrial wastewater fraction) and BTBPE, but also had moderate correlation with APV (actual processing volume) and SP (serving population). Component 2 accounted for $13.0 \%$ of the total variance and had strong positive loadings on DP, APV, SP. The score plot of PCA in Figure 2 was grouped by sewage source of WWTPs (DW: domestic wastewater; MW: mixed domestic and industrial wastewater), which indicated the pattern profiles of HFRs in DW and MW in China are rather different. Combing the visualization of loading and score plot, PCA results implied DBDPE, HBCD, and BTBPE were the predominant compounds among the targeted HFRs in most of the MW source sludge. The cluster of these compounds with TOC 

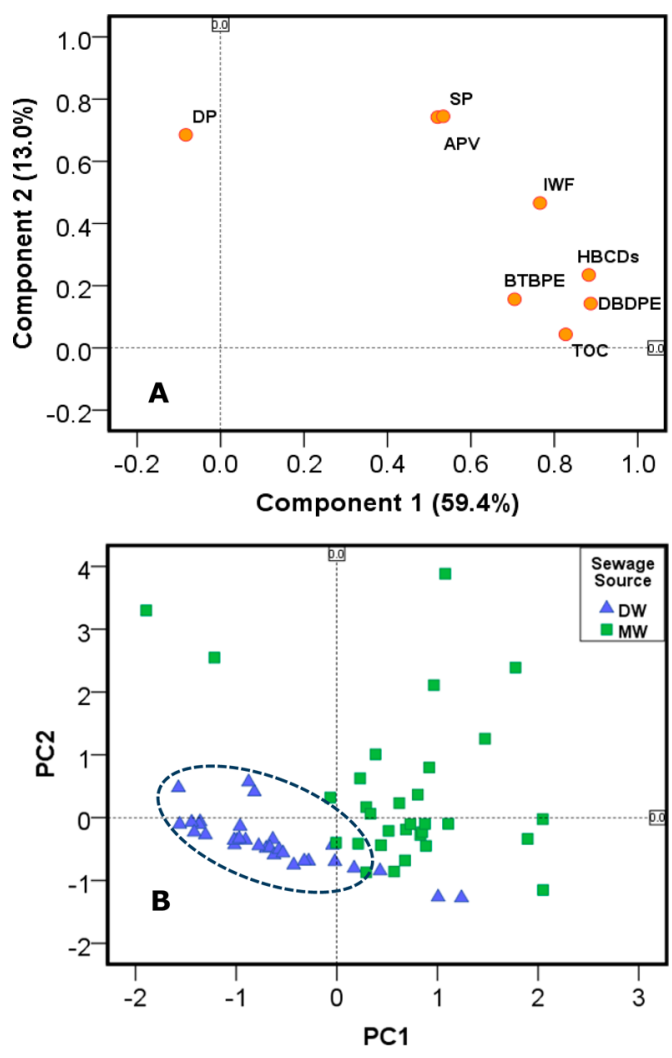

Figure 2. Loading plot (A) and score plot (B) (grouped by sewage source, DW: domestic wastewater; MW: mixed domestic and industrial wastewater) of HFRs concentrations in all sludge samples from the principal component analysis.

suggested that TOC might be a major factor for BFRs governing the transport and solids-liquid distribution. Industrial wastewater could be a more important source for the BFRs relative to domestic wastewater. Moreover, DP was separated from the three HFRs and negatively correlated with the three HFRs and TOC in some WWTPs, likely reflecting different use patterns of these chemicals in the regions. Leakage of DP from consumer goods via domestic wastewater could favor the association of DP with the DW source sludge.

Pearson's correlation analysis show significant relationships exist between ln-transformed HFRs concentrations (ln HFRs) and industrial wastewater fraction (ln IWF) $(R=0.544-0.662$, $p<0.05$ ), further suggesting that release of these compounds is associated with industrial activity, which is in agreement with De la Torre's previous report. ${ }^{32}$ Besides, ln-transformed concentrations of DBDPE, HBCD, BTBPE and DP were also correlated with sludge TOC ( $\ln$ TOC) $(R=0.562-0.848, p<$ $0.05)$, actual processing volume (ln APV) $(R=0.555-0.659, p$ $<0.05)$ and serving population (ln SP) $(R=0.632-0.731, p<$ $0.05)$. A similar relationship between population density and HFRs concentrations can also observed for the council districts of Hong Kong. ${ }^{12}$ This provides a general indication that levels of emerging HFRs in sewage sludge tend to be higher in those WWTPs with larger daily loading per capita. So, highly elevated levels of DBDPE, HBCD, and DP in sludge samples (NO.5, 6, 43, 44 in SI Table S3) could be influenced by the dense population and intensive industrial activities.

MLR Modeling to Help Predict HFR Levels in Sewage Sludge with TOC and the Major WWTP Characteristics. Multivariate linear regression (MLR) was tentatively performed to predict HFR levels in Chinese sewage sludge with TOC and the major concentration-related WWTP characteristics, including IWF, APV, and SP. The concentrations of the dominant HFRs such as BTBPE, DBDPE, $\sum$ HBCD, and $\sum D P$ in sewage sludge could be predicted from TOC and three major WWTP characteristics using the four-variable models with statistical significance. The linear regression equations as Ln Analyte $=a$ $+b \times \operatorname{Ln} \mathrm{TOC} \%+c \times \operatorname{Ln} \mathrm{APV}+d \times \operatorname{Ln} \mathrm{IWF}+e \times \operatorname{Ln~SP}(p<$ $0.05)$ are shown in Table 3.

Table 3. Multivariate Linear Regression Equation as Ln Analyte $=a+b \times \operatorname{Ln} \mathrm{TOC} \%+c \times \mathrm{Ln} \mathrm{APV}+d \times \mathrm{Ln} \mathrm{IWF}+e$ $\times$ Ln SP $(p<0.05)$ for Four Dominant Flame Retardants in Chinese Sewage Sludge

$\begin{array}{lcccccc}\text { analyte } & a & b & c & d & e & R^{2} \\ \text { BTBPE } & -2.08 & 0.17 & 0.22 & 0.21 & 0.22 & 0.490 \\ \text { DBDPE } & 0.13 & 0.32 & 0.40 & 0.38 & 0.41 & 0.591 \\ \sum \text { HBCD } & -0.06 & 0.25 & 0.31 & 0.30 & 0.32 & 0.666 \\ \sum \text { DP } & -2.10 & 0.36 & 0.46 & 0.44 & 0.47 & 0.506\end{array}$

The MLR analysis can explain about $49-67 \%$ of the variability in predicting the concentrations of BTBPE, DBDPE, $\sum$ HBCD, and $\sum$ DP in sludge. Comparisons of the predicted with measured concentrations are shown in Figure 3.

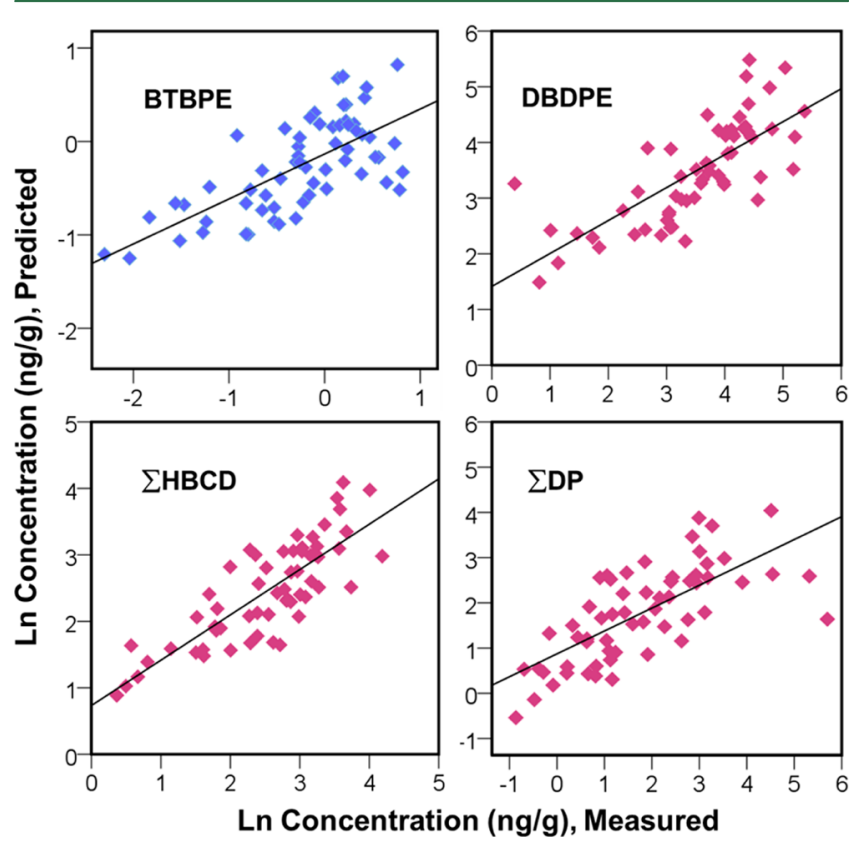

Figure 3. Predicted versus measured concentration (ng/g, d.w.) for BTBPE $\left(n=62, R^{2}=0.490, p<0.05\right)$, DBDPE $\left(n=62, R^{2}=0.591, p\right.$ $<0.05), \sum \operatorname{HBCD}\left(n=61, R^{2}=0.666, p<0.05\right)$, and $\sum \mathrm{DP}(n=60$, $\left.R^{2}=0.506, p<0.05\right)$ in the sludge samples by the principal component regression.

The deviation of the slope from the 1:1 ideal line indicates that the models overestimate the measured values at their lower levels while somewhat underestimate them at their higher levels, which might be due to failure to consider hydraulic retention time (HRT) during wastewater treatment and other unknown factors. The models can help to evaluate the pollution levels of these PBDE substitutes in WWTPs sludge, but their subsequent environmental emission through sludge disposal remain unclear. 
Estimation of HFR Accumulation in Sewage Sludge and Their Release into Biosolids-Applied Soils. In China, there were 4136 municipal WWTPs treating about 126000 tons wastewater on a daily basis in $2013 .{ }^{68}$ Approximately 30 million tons of sludge were produced on annual basis from the nationwide WWTPs. ${ }^{69}$ Sludge disposal in China is generally composed of landfill burial (63\%), land application (15\%), incineration (2\%), building materials (3\%), and other (17\%). ${ }^{69}$ To evaluate impact of these contaminants in the environment, the nationwide annual emission fluxes of DBDPE, HBCD, DP, and BTBPE were calculated using total sludge production volume. Based on the measured concentrations, the estimate emission fluxes were 1566,519,567, and $28.5 \mathrm{~kg} /$ year for DBDPE, HBCD, DP, and BTBPE, respectively. Comparing the total annual accumulation in sewage sludge to the annual production volume in China suggests that the leakage of DBDPE, HBCD, and DP from the technosphere via municipal wastewater was of the order of $0.01 \%, 0.01 \%$, and $0.06-0.2 \%$, respectively. These small fractions may be attributed to low treatment rate of wastewater and large exportation of the produced HFRs in China. The proportion of biosolids for land application in China is relatively low. Most of them were directly used as fertilizers in agriculture fields near the WWTPs. The amounts of DBDPE, HBCD, DP, and BTBPE released into the biosolids-applied soils were estimated to $235,78,85$, and $4.3 \mathrm{~kg} /$ year. Up to now, little is known about the ultimate fate and environmental impact of emerging HFRs in the biosoilds-applied soils. More monitoring studies are urgently needed to provide more information for future environmental risk assessment and management.

\section{ASSOCIATED CONTENT}

\section{S Supporting Information}

Additional information on sample preparation and cleanup, WWTP characteristics for each sludge samples (Table S1), structure information for all analytes (Table S2), dry-weigh basis and TOC- normalized concentration data (Table S3 and S4), tables of data for global comparison on the basis of available concentrations (Table S5-7), the sampling map (Figure S1), representative chromatograms (Figure S2-4), Box-Whisker plots (Figure S5) and spatial distribution in two typical regions (Figure S6). This material is available free of charge via the Internet at http://pubs.acs.org.

\section{AUTHOR INFORMATION}

\section{Corresponding Author}

*Phone: 8610-6284-9334; fax: 8610-6284-9339; e-mail: ywwang@rcees.ac.cn.

\section{Notes}

The authors declare no competing financial interest.

\section{ACKNOWLEDGMENTS}

This work was supported by the National Natural Science Foundation (21377001, 21222702, 21107122), the Beijing NOVA Programme (Z131109000413049), the Strategic Priority Research Program of the Chinese Academy of Sciences (XDB14010400) and the President Fund of UCAS (Y25101BY00).

\section{REFERENCES}

(1) Salamova, A.; Hites, R. A. Brominated and chlorinated flame retardants in tree bark from around the globe. Environ. Sci. Technol. 2013, 47 (1), 349-354.

(2) Covaci, A.; Harrad, S.; Abdallah, M. A. E.; Ali, N.; Law, R. J.; Herzke, D.; de Wit, C. A. Novel brominated flame retardants: A review of their analysis, environmental fate and behaviour. Environ. Int. 2011, 37 (2), 532-556.

(3) Sverko, E.; Tomy, G. T.; Reiner, E. J.; Li, Y. F.; McCarry, B. E.; Arnot, J. A.; Law, R. J.; Hites, R. A. Dechlorane Plus and related compounds in the environment: A review. Environ. Sci. Technol. 2011, 45 (12), 5088-5098.

(4) Arinaitwe, K.; Muir, D. C. G.; Kiremire, B. T.; Fellin, P.; Li, H.; Teixeira, C. Polybrominated diphenyl ethers and alternative flame retardants in air and precipitation samples from the Northern Lake Victoria Region, East Africa. Environ. Sci. Technol. 2014, 48 (3), 14581466.

(5) Salamova, A.; Hites, R. A. Discontinued and alternative brominated flame retardants in the atmosphere and precipitation from the Great Lakes Basin. Environ. Sci. Technol. 2011, 45 (20), $8698-8706$

(6) Luo, X.; Chen, S.; Mai, B.; Fu, J. Advances in the study of currentuse non-PBDE brominated flame retardants and dechlorane plus in the environment and humans. Sci. China: Chem. 2010, 53 (5), 961973.

(7) Yang, R. Q.; Wei, H.; Guo, J. H.; Li, A. Emerging brominated flame retardants in the sediment of the Great Lakes. Environ. Sci. Technol. 2012, 46 (6), 3119-3126.

(8) La Guardia, M. J.; Hale, R. C.; Harvey, E.; Mainor, T. M.; Ciparis, S. In situ accumulation of HBCD, PBDEs, and several alternative flame-retardants in the bivalve (Corbicula fluminea) and gastropod (Elimia proxima). Environ. Sci. Technol. 2012, 46 (11), 5798-5805.

(9) Tian, M.; Chen, S. J.; Wang, J.; Shi, T.; Luo, X. J.; Mai, B. X. Atmospheric deposition of halogenated flame retardants at urban, ewaste, and rural locations in southern China. Environ. Sci. Technol. 2011, 45 (11), 4696-4701.

(10) Chen, S. J.; Feng, A. H.; He, M. J.; Chen, M. Y.; Luo, X. J.; Mai, B. X. Current levels and composition profiles of PBDEs and alternative flame retardants in surface sediments from the Pearl River Delta, southern China: Comparison with historical data. Sci. Total Environ. 2013, 444, 205-211.

(11) Shi, T.; Chen, S. J.; Luo, X. J.; Zhang, X. L.; Tang, C. M.; Luo, Y.; Ma, Y. J.; Wu, J. P.; Peng, X. Z.; Mai, B. X. Occurrence of brominated flame retardants other than polybrominated diphenyl ethers in environmental and biota samples from southern China. Chemosphere 2009, 74 (7), 910-916.

(12) Liu, H. H.; Hu, Y. J.; Luo, P.; Bao, L. J.; Qiu, J. W.; Leung, K. M. Y.; Zeng, E. Y. Occurrence of halogenated flame retardants in sediment off an urbanized coastal zone: Association with urbanization and industrialization. Environ. Sci. Technol. 2014, 48, 8465-8473.

(13) Zhu, B.; Lai, N. L. S.; Wai, T.-C.; Chan, L. L.; Lam, J. C. W.; Lam, P. K. S. Changes of accumulation profiles from PBDEs to brominated and chlorinated alternatives in marine mammals from the South China Sea. Environ. Int. 2014, 66, 65-70.

(14) Wang, D. G.; Yang, M.; Qi, H.; Sverko, E.; Ma, W. L.; Li, Y. F.; Alaee, M.; Reiner, E. J.; Shen, L. An asia-specific source of Dechlorane Plus: Concentration, isomer profiles, and other related compounds. Environ. Sci. Technol. 2010, 44 (17), 6608-6613.

(15) Venier, M.; Ma, Y. N.; Hites, R. A. Bromobenzene flame retardants in the Great Lakes atmosphere. Environ. Sci. Technol. 2012, 46 (16), 8653-8660.

(16) Wu, J.-P.; Guan, Y.-T.; Zhang, Y.; Luo, X.-J.; Zhi, H.; Chen, S.-J.; Mai, B.-X. Several current-use, non-PBDE brominated flame retardants are highly bioaccumulative: Evidence from field determined bioaccumulation factors. Environ. Int. 2011, 37 (1), 210-215.

(17) Szymanska, J. A. Hepatotoxicity of brominated benzenes: Relationship between chemical structure and hepatotoxic effects in acute intoxication of mice. Arc. TOC 1998, 72 (2), 97-103. 
(18) Ren, N. Q.; Sverko, E.; Li, Y. F.; Zhang, Z.; Harner, T.; Wang, D. G.; Wan, X. N.; McCarry, B. E. Levels and isomer profiles of Dechlorane Plus in Chinese air. Environ. Sci. Technol. 2008, 42 (17), 6476-6480.

(19) Hoh, E.; Zhu, L. Y.; Hites, R. A. Dechlorane Plus, a chlorinated flame retardant, in the Great Lakes. Environ. Sci. Technol. 2006, 40 (4), 1184-1189.

(20) Shen, L.; Reiner, E. J.; Macpherson, K. A.; Kolic, T. M.; Sverko, E.; Helm, P. A.; Bhavsar, S. P.; Brindle, I. D.; Marvin, C. H. Identification and screening analysis of halogenated norhornene flame retardants in the Laurentian Great Lakes: Dechloranes 602, 603, and 604. Environ. Sci. Technol. 2010, 44 (2), 760-766.

(21) M?ller, A.; Xie, Z. Y.; Sturm, R.; Ebinghaus, R. Large-scale distribution of Dechlorane Plus in air and seawater from the Arctic to Antarctica. Environ. Sci. Technol. 2010, 44 (23), 8977-8982.

(22) Lee, S.; Song, G. J.; Kannan, K.; Moon, H. B. Occurrence of PBDEs and other alternative brominated flame retardants in sludge from wastewater treatment plants in Korea. Sci. Total Environ. 2014, 470, 1422-1429.

(23) Subedi, B.; Lee, S.; Moon, H. B.; Kannan, K. Psychoactive pharmaceuticals in sludge and their emission from wastewater treatment facilities in Korea. Environ. Sci. Technol. 2013, 47 (23), $13321-13329$.

(24) Harrison, E. Z.; Oakes, S. R.; Hysell, M.; Hay, A. Organic chemicals in sewage sludges. Sci. Total Environ. 2006, 367 (2-3), 481-497.

(25) Gorga, M.; Martinez, E.; Ginebreda, A.; Eljarrat, E.; Barcelo, D. Determination of PBDEs, HBB, PBEB, DBDPE, HBCD, TBBPA and related compounds in sewage sludge from Catalonia (Spain). Sci. Total Environ. 2013, 444, 51-59.

(26) Clarke, B. O.; Smith, S. R. Review of 'emerging' organic contaminants in biosolids and assessment of international research priorities for the agricultural use of biosolids. Environ. Int. 2011, 37 (1), 226-247.

(27) Baron, E.; Santin, G.; Eljarrat, E.; Barcelo, D. Occurrence of classic and emerging halogenated flame retardants in sediment and sludge from Ebro and Llobregat river basins (Spain). J. Hazard. Mater. 2014, 265, 288-295.

(28) Hwang, I. K.; Kang, H. H.; Lee, I. S.; Oh, J. E. Assessment of characteristic distribution of PCDD/Fs and BFRs in sludge generated at municipal and industrial wastewater treatment plants. Chemosphere 2012, 88 (7), 888-894.

(29) Davis, E. F.; Klosterhaus, S. L.; Stapleton, H. M. Measurement of flame retardants and triclosan in municipal sewage sludge and biosolids. Environ. Int. 2012, 40, 1-7.

(30) Ricklund, N.; Kierkegaard, A.; McLachlan, M. S. An international survey of decabromodiphenyl ethane (deBDethane) and decabromodiphenyl ether (decaBDE) in sewage sludge samples. Chemosphere 2008, 73 (11), 1799-1804.

(31) De la Torre, A.; Concejero, M. A.; Martinez, M. A. Concentrations and sources of an emerging pollutant, decabromodiphenylethane (DBDPE), in sewage sludge for land application. $J$. Envion. Sci. 2012, 24 (3), 558-563.

(32) De la Torre, A.; Sverko, E.; Alaee, M.; Martinez, M. A. Concentrations and sources of Dechlorane Plus in sewage sludge. Chemosphere 2011, 82 (5), 692-697.

(33) Nyholm, J. R.; Grabic, R.; Arp, H. P. H.; Moskeland, T.; Andersson, P. L. Environmental occurrence of emerging and legacy brominated flame retardants near suspected sources in Norway. Sci. Total Environ. 2013, 443, 307-314.

(34) Kierkegaard, A.; Bjorklund, J.; Friden, U. Identification of the flame retardant decabromodiphenyl ethane in the environment. Environ. Sci. Technol. 2004, 38 (12), 3247-3253.

(35) Zhang, X. Y.; Lu, Q. Y. Production status and developing prospects of flame retardants. China Plast Ind. 2011, 39, 1-5.

(36) Zhou, Z. M. Implement of administrative measure on the control of pollution caused by electronic information products and the exemption of deca-BDE mixture. Chin. J. Flame Retard. Mater. Technol. 2006, 4, 15-16.
(37) Jiang, Y. Q. The status quo and development of brominated flame retardants. Chin. J. Flame Retard. Mater. Technol. 2007, 2, 1-7. (38) Flame Retardants, Chemical Insight and Forecasting: IHS Chemical. 2011. http://www.ihs.com/products/chemical/planning/ scup/flame-retardants.aspx. .

(39) Zhu, B. Q.; Lam, J. C. W.; Yang, S. Y.; Lam, P. K. S. Conventional and emerging halogenated flame retardants (HFRs) in sediment of Yangtze River Delta (YRD) region, East China. Chemosphere 2013, 93 (3), 555-560.

(40) Wu, J. P.; Guan, Y. T.; Zhang, Y.; Luo, X. J.; Zhi, H.; Chen, S. J.; Mai, B. X. Trophodynamics of hexabromocyclododecanes and several other non-PBDE brominated flame retardants in a freshwater food web. Environ. Sci. Technol. 2010, 44 (14), 5490-5495.

(41) Wang, D. G.; Alaee, M.; Sverko, E.; Li, Y. F.; Reiner, E. J.; Shen, L. Analysis and occurrence of emerging chlorinated and brominated flame retardants in surficial sediment of the Dalian costal area in China. J. Environ. Monit. 2011, 13 (11), 3104-3110.

(42) Yang, R. Q.; Wei, H.; Guo, J. H.; McLeod, C.; Li, A.; Sturchio, N. C. Historically and Currently Used Dechloranes in the Sediments of the Great Lakes. Environ. Sci. Technol. 2011, 45 (12), 5156-5163.

(43) Zhang, H. D.; Wang, P.; Li, Y. M.; Shang, H. T.; Wang, Y. W.; Wang, T.; Zhang, Q. H.; Jiang, G. B. Assessment on the occupational exposure of manufacturing workers to Dechlorane Plus through blood and hair analysis. Environ. Sci. Technol. 2013, 47 (18), 10567-10573.

(44) Brandsma, S. H.; van der Ven, L. T. M.; de Boer, J.; Leonards, P. E. G. Identification of hydroxylated metabolites of hexabromocyclododecane in wildlife and 28-days exposed wistar rats. Environ. Sci. Technol. 2009, 43 (15), 6058-6063.

(45) Wang, Y. W.; Zhang, Q. H.; Lv, J. X.; Li, A.; Liu, H. X.; Li, G. G.; Jiang, G. B. Polybrominated diphenyl ethers and organochlorine pesticides in sewage sludge of wastewater treatment plants in China. Chemosphere 2007, 68 (9), 1683-1691.

(46) Sun, J. T.; Liu, J. Y.; Liu, Q.; Ruan, T.; Yu, M.; Wang, Y. W.; Wang, T.; Jiang, G. B. Hydroxylated polybrominated diphenyl ethers (OH-PBDEs) in biosolids from municipal wastewater treatment plants in China. Chemosphere 2013, 90 (9), 2388-2395.

(47) Ruan, T.; Song, S. J.; Wang, T.; Liu, R. Z.; Lin, Y. F.; G.B, J. Identification and composition of emerging quaternary ammonium compounds in municipal sewage sludge in China. Environ. Sci. Technol. 2014, 48 (8), 4289-4297.

(48) Zhou, Z. M. Brominated Flame Retardants: The main force for flame-retardant materials (in Chinese). Eng. Plast. Appl. 2006, No. 12, 41.

(49) Oh, J. K.; Kotani, K.; Managaki, S.; Masunaga, S. Levels and distribution of hexabromocyclododecane and its lower brominated derivative in Japanese riverine environment. Chemosphere 2014, 109, 157-163.

(50) Abdallah, M. A. E.; Harrad, S. Personal exposure to HBCDs and its degradation products via ingestion of indoor dust. Environ. Int. 2009, 35 (6), 870-876.

(51) Tomy, G. T.; Palace, V.; Marvin, C.; Stapleton, H. M.; Covaci, A.; Harrad, S. Biotransformation of HBCD in biological systems can confound temporal-trend studies. Environ. Sci. Technol. 2011, 45, 364365 .

(52) Abdallah, M. A.; Uchea, C.; Chipman, J. K.; Harrad, S. Enantioselective biotransformation of hexabromocyclododecane by in vitro rat and trout hepatic sub-cellular fractions. Environ. Sci. Technol. 2014, 48 (5), 2732-2740.

(53) Hakk, H.; Szabo, D. T.; Huwe, J.; Diliberto, J.; Birnbaum, L. S. Novel and distinct metabolites identified following a single oral dose of alpha- or gamma-hexabromocyclododecane in mice. Environ. Sci. Technol. 2012, 46 (24), 13494-13503.

(54) Carignan, C. C.; Abdallah, M. A. E.; Wu, N.; Heiger-Bernays, W.; McClean, M. D.; Harrad, S.; Webster, T. F. Predictors of tetrabromobisphenol-A (TBBP-A) and hexabromocyclododecanes (HBCD) in milk from Boston mothers. Environ. Sci. Technol. 2012, 46 (21), 12146-12153.

(55) Sverko, E.; Tomy, G. T.; Marvin, C. H.; Zaruk, D.; Reiner, E.; Helm, P. A.; Hill, B.; McCarry, B. E. Dechlorane Plus levels in 
sediment of the lower Great Lakes. Environ. Sci. Technol. 2008, 42 (2), 361-366.

(56) Qi, H.; Liu, L. Y.; Jia, H. L.; Li, Y. F.; Ren, N. Q.; You, H.; Shi, X. Y.; Fan, L. L.; Ding, Y. S. Dechlorane Plus in surficial water and sediment in a northeastern Chinese river. Environ. Sci. Technol. 2010, 44 (7), 2305-2308.

(57) Ma, W. L.; Liu, L. Y.; Hong, Q. A.; Sun, D. Z.; Shen, J. M.; Wang, D. G.; Li, Y. F. Dechlorane plus in multimedia in northeastern Chinese urban region. Environ. Int. 2011, 37 (1), 66-70.

(58) Zhang, Y.; Wu, J. P.; Luo, X. J.; Wang, J.; Chen, S. J.; Mai, B. X. Tissue distribution of Dechlorane Plus and its dechlorinated analogs in contaminated fish: High affinity to the brain for anti-DP. Environ. Pollut. 2011, 159 (12), 3647-3652.

(59) Munoz-Arnanz, J.; Saez, M.; Hiraldo, F.; Baos, R.; Pacepavicius, G.; Alaee, M.; Jimenez, B. Dechlorane plus and possible degradation products in white stork eggs from Spain. Environ. Int. 2011, 37 (7), $1164-1168$.

(60) Ben, Y. J.; Li, X. H.; Yang, Y. L.; Li, L.; Zheng, M. Y.; Wang, W. Y.; Xu, X. B. Placental transfer of Dechlorane Plus in mother-infant pairs in an e-waste recycling area (Wenling, China). Environ. Sci. Technol. 2014, 48, 5187-5193.

(61) Zhao, Z.; Zhong, G. C.; M?ller, A.; Xie, Z. Y.; Sturm, R.; Ebinghaus, R.; Tang, J. H.; Zhang, G. Levels and distribution of Dechlorane Plus in coastal sediments of the Yellow Sea, North China. Chemosphere 2011, 83 (7), 984-990.

(62) Kuch, B.; Schneider, C.; Metzger, J.; Weber, R. Hexabromobenzene and pentabromophenol in German sewage sludgeIndication of significant commercial use. Organohalog. Compd. 2005, 67, 434-437.

(63) Guerra, P.; Eljarrat, E.; Barcelo, D. Simultaneous determination of hexabromocyclododecane, tetrabromobisphenol $\mathrm{A}$, and related compounds in sewage sludge and sediment samples from Ebro River basin (Spain). Anal. Bioanal. Chem. 2010, 397 (7), 2817-2824.

(64) Law, R. J.; Allchin, C. R.; de Boer, J.; Covaci, A.; Herzke, D.; Lepom, P.; Morris, S.; Tronczynski, J.; de Wit, C. A. Levels and trends of brominated flame retardants in the European environment. Chemosphere 2006, 64 (2), 187-208.

(65) Kupper, T.; de Alencastro, L. F.; Gatsigazi, R.; Furrer, R.; Grandjean, D.; Tarradellas, J. Concentrations and specific loads of brominated flame retardants in sewage sludge. Chemosphere 2008, 71 (6), 1173-1180.

(66) Morris, S.; Allchin, C. R.; Zegers, B. N.; Haftka, J. J. H.; Boon, J. P.; Belpaire, C.; Leonards, P. E. G.; Van Leeuwen, S. P. J.; De Boer, J. Distributon and fate of $\mathrm{HBCD}$ and TBBPA brominated flame retardants in north sea estuaries and aquatic food webs. Environ. Sci. Technol. 2004, 38 (21), 5497-5504.

(67) Persistent Organic Pollutants Review Committee, Risk Profile on Hexabromocyclododecanes, UNEP/POPS/POPRC.6/13/Add.2; Stockholm Convention on Persistent Organic Pollutants: Geneva, 2010.

(68) Ministry of Environment (MOE). List of Nationwide Municipal Wastewater Treatment Plants Facilities in 2013, Beijing, China (in Chinese): Ministry of Environment (000014672/2014-00326). 2014.

(69) Dong, J.; Zhai, Y. C.; Liu, S. H.; Liu, M. Present situation and development tendency of sludge land application of wastewater treatment plants (in Chinese). Ind. Saf. Environ. Prot. 2013, 39 (4), $43-45$. 